\title{
Global determinants of sustaining and developing family enterprises in Slovakia
}

\author{
Mária Moresová ${ }^{1}$, Mariana Sedliačiková ${ }^{1, *}$, and Alena Kaščáková ${ }^{2}$ \\ ${ }^{1}$ Technical University in Zvolen, Faculty of Wood Sciences and Technology, Department of \\ Economics, Management and Business, T. G. Masaryka 24, 96001 Zvolen, Slovakia \\ ${ }^{2}$ Matej Bel University in Banská Bystrica, Faculty of Economics, Department of Quantitative \\ Methods and Information Systems, Tajovského 10, 97590 Banská Bystrica, Slovakia
}

\begin{abstract}
Family enterprises play an important role in global economies and in national economies of all developed countries. Creating new, and maintaining the existing family enterprises, combined with their continuous development should be the key priority of all countries. Based on the evaluation of the current state of family business in Slovak micro, small, and medium enterprises, the main objective of this paper is to identify the key determinants which affect its development. At the same time, the authors propose such measures the implementation of which into business practice will lead to sustainability of the existing, as well as the support of the newly established family enterprises in Slovakia. The research has been evaluated with the use of methods of testing the statistical hypothesis and methods of descriptive statistics. As the conducted research has proved, at the external environment, the most negative determinant that limits the activities of family enterprises is strong competition of other enterprises operating in the Slovak market. The biggest problem related to internal environment of family enterprises is obtaining a stable qualified. The results led to conclusions and recommendations, the implementation of which into practice will help to support family business in Slovakia.
\end{abstract}

\section{Introduction}

The business environment (BE) significantly determines the increase of productivity, innovation, investments, and establishing new jobs. In order to enable entrepreneurship in a country, it is essential to create such environment that would not impose barriers that would disable or limit business activities. In global business environment, the last decade has witnessed a great attention aimed towards family enterprises [1,2,3]. In market economies, family business has a long tradition. More than two thirds of all enterprises are family enterprises (FE), the existence and creation of which dates back to distant past in Western Europe, while at the same time reflecting the present times. FE have the largest representation in the segment of micro, small, and medium enterprises. It must be pointed out that FE have been a solid way of doing business, verified by many centuries, which

*Corresponding author: $\underline{\text { sedliacikova@tuzvo.sk }}$ 
provides a family - as well as the whole society - with a number of social and economic benefits. FE are known by their distinct internal atmosphere, which offers a platform to interaction between the hard entrepreneurial climate and the hearty family relations $[4,5]$.

In Slovakia, this specific business segment has been given little attention. It may be caused partly by the fact that entrepreneurship is a relatively young discipline in the modern history of Slovakia, since the private sector has only been developing here since 1989. At present, Slovak FE are not in any way specifically distinguished from non-family enterprises, for the lack of being defined as such, and thus being distinctly differentiated [6]. FE, however, may be characterized by numerous specific aspects that differentiate them from non-family enterprises [4,7]. Based on the evaluation of the current state of family business in Slovak micro, small, and medium enterprises, the main objective of this paper is to identify the key determinants which affect its development. At the same time, the authors propose such measures the implementation of which into business practice will lead to sustainability of the existing, as well as the support of the newly established FE in Slovakia.

Business is influenced by many determinants, which altogether form the business environment. It is essential that all enterprises communicate actively and monitor their environment, since BE has a direct effect on their development, as well as their existence. $\mathrm{BE}$ can be defined as a combination of internal and external determinants which affect the activities of an enterprise. External determinants are those factors that provide all enterprises in a market with an opportunity, or represent a threat for their business activities. As to the external determinants, BE can be divided into two main categories, i.e. macro and micro environment, and their determinants. If an enterprise wants to become successful in the market, it is essential for it to understand which determinants influence its development. As soon as an enterprise identifies the positive and the negative effects of determinants in the $\mathrm{BE}$, it can create appropriate strategies to manage every possible situation. Examining the internal and external factors thus represents the most important task for the enterprise in the context of establishing it, maintaining its existence, or responding to the changes in business plans and strategies. On the other hand, it is absolutely essential that the individual countries themselves create such environment that will be appropriate for performing the business activities of family enterprises $[8,9,10]$.

\section{Methodology}

The methodology of the paper is divided into four phases. Within the first phase of our research, it was necessary to summarize the results of the analysis of Slovak, but mainly foreign, secondary sources. This phase used methods such as summarizing, synthesis of the knowledge, as well as the method of analogy and deduction. The second phase focused on the analysis of primary sources obtained from an empirical research, through the questioning method. The questionnaire was aimed at finding out the key external and internal determinants which represent barriers to development of FE in Slovakia. Since no unified concept of FE has been defined, and at the same time family business as such is not defined in Slovak legislation, the authors have adopted a definition of FE as proposed by the EU. This means that FE is such enterprise that can be characterized by at least one of the following elements [7, 11]: one or more family members have established (acquired) the enterprise, and are the majority (or full) decision makers; the enterprise is owned by a spouse, parents, children, or direct descendants of the owners; at least one of the family members (or relatives) participates in the management and administration of the enterprise; while in listed enterprises, one family owns at least $25 \%$ of the voting rights. The questionnaire was sent to 5,910 SMEs which operate in the Slovak market. The questionnaires were distributed electronically. As many as 1,052 of the filled-in questionnaires have returned, which represents the return rate of $17.8 \%$. Of this number of 
enterprises who participated in the research, 884 fulfilled the condition of being defined as a family enterprise (15\% return rate). Based on the available literary sources, four main hypotheses were determined.

Macro-environment is defined by [12] as a general environment that influences all enterprises simultaneously. Determinants of this environment must be fully respected by all business subjects, while they have no power to influence it. Determinants of the macroenvironment are divided by [13] into six basic groups: political and legal; economic; demographic; social-cultural; technological and informational; and ecological. Specific environment created in a country may have a large effect on the performance and sustainability of family enterprises; and as noted by the scholars [12], the political and legal factor is thus considered to be the central factor of the macro-environment. The government of a country in this case acts as the main institution which has the largest influence on creating the macro-environment, and can significantly affect sustainability of family enterprises, and at the same time provide support to newly established FE in Slovakia.

$H_{1}$ : We assume that at the macro-environmental level, most micro, small and medium family enterprises (MSMFE) in Slovakia consider the political and legal determinants to be the factor that influences their business in a most negative way.

Micro-environment is defined by [12] as a narrower external environment which is in direct contact with the business subjects, and can influence common business activities immediately. Micro-environment consists of the competition, suppliers, customers, intermediaries, and other entrepreneurs along with the public. As noted by $[7,12,14]$, it is a worldwide trend that FE are becoming more and more competitive. Fast technological changes and interferential innovations represent the basic elements which accelerate this process. FE are facing competitive challenges on many sides. While on one hand, FE need to quickly adapt to the changing $\mathrm{BE}$, on the other, they must tackle issues and tendencies within the family. [6] emphasizes the changes the BE in the Slovak Republic was subjected to after Slovakia had entered the EU. Besides the changes related to liberalization of the trade relations with the EU (and others), the Slovak market has experienced a massive growth in the number of competing enterprises from the western world. This means that currently, Slovak FE are facing not only domestic but also strong international competition in the Slovak market.

$\mathrm{H}_{2}$ : We assume that at the micro-environmental level (narrower external environment), the main external problem of Slovak MSMFE is competition of other enterprises which operate in the Slovak market.

As presented by [11,12], the existence and development of an enterprise is largely dependent on its strengths and its ability to adapt to changes in the BE. The internal determinants of an enterprise thus relate to virtually anything within its operations. Among the basic determinants of the internal environment of an enterprise belong: management, finances, human resources, marketing, and $R \& D$. The mentioned determinants of the internal environment, according to [6], are considered to be fully controllable factors, which the enterprise may alter according to the needs of the external BE. Foreign authors $[5,15]$ assume that FE should elaborate a so called family protocol right at the establishment of the enterprise. Its main role would be to regulate the relations among the family members, as well as between the family and the enterprise. The family protocol enables formulating a set of norms related to family members and the whole administration, planning the succession, preparing and educating members of the family, regulating the relations between the owners of an enterprises and the other employees, legal structure, solving conflicts (mainly among the family members), and dealing with the ways of distributing profit (or paying the dividends in listed enterprises). As proved by a thorough investigation [15], Slovak family enterprises do not possess sufficient experience with managing FE. Tradition of FE in Slovakia had been cut off and was only renewed after 1989. Public institutions in the 
Slovak Republic have not paid enough attention to family business, which, unlike in western countries, did not benefit from the opportunities of various support grants, programs or trainings, where they would learn about the contemporary recommendations from more experienced FE and from the academic sphere. Foreign authors [7, 15,16] point out that FE which have applied family protocols straight from the beginning of their existence, have integrated their individual interests into one unit, they monitor the effectivity of their management, and unite professionalism with the family approach to filling-in the working positions in the enterprise. By regulating relations in the workplace, an enterprise prevents the influence of personal conflicts of the family members into business environment. Conflicts of family employees themselves greatly affect all determinants of the internal environment. In case the rules of behavior and the direction of the enterprise are not clearly determined, it can have a significantly negative effect on family business.

$H_{3}$ : We assume that MSMFE which have not elaborated their family protocol, perceive the selected determinants of their internal environment in a more negative way that those who have the protocol defined.

According to scholars [4, 7, 17] FE prefer to employ family members. Almost all FE pay attention to creating job positions mainly for the members of family. It is, unfortunately, common that family employees do not possess sufficient qualifications, and the enterprise is forced to employ external (non-family) employees. The external employees often work in the enterprise for several years, while the enterprise invests into their education, and into training their skills and competences. After achieving own experience, external employees often leave the FE which have invested into them, and establish their own enterprises. For FE, this represents a great loss, and forces them to look for new qualified employees in the job market. According to [15], the lack of qualified workforce is a great problem of the contemporary Slovak job market. The main reason appears to be lack of interest among students to study technical subjects. Another problem of the contemporary Slovak society is the 'brain drain' to more developed countries.

$\mathrm{H}_{4}$ : We assume that the main internal problem of Slovak MSMFE is the inability to obtain a stable qualified workforce.

In order to evaluate the above hypotheses, the selected mathematic and statistical methods were used: Chi-square test, Binomial test, Friedman test, Wilcoxon test, and the Mann-Whitney test. Within the third phase, recommendations were proposed, the implementation of which into business practice will lead to sustainability of the existing, as well as to support of the newly established family enterprises in Slovakia. In the third phase, the methods of analysis, comparison, deduction and summary were used.

\section{Results and discussion}

The following section presents the results of a questionnaire and verification of the hypotheses focused on identifying the determinants of the external and internal environment of micro, small, and medium family enterprises.

Altogether, 884 family enterprises have participated in the research, while 859 rank among micro FE, 20 are small, and 5 are medium FE. The representativeness of the sample was verified by non-parametric Chi-square test in the statistical program SPSS. To test the statistical hypotheses, the level of significance was determined at 0.05 . From the results of the test, it can be concluded that the selected sample is representative according to the criterion of the size of enterprise ( $\mathrm{p}$-value $=0.960$ ). Based on the question aimed at identifying the FE, all $884 \mathrm{FE}$ which were addressed by the questionnaire research agree with the statement that one or more members of the family have established, or acquired the enterprise, and are the majority or full decision makers. Since the respondents could 
indicate more options in answering this question, the second most frequent characteristic feature of FE was that at least one of the family members (or a relative) participates in the management or administration of the enterprise (100\% of the addressed FE).

In the next part, the external determinants influencing the business operations of FE were examined. FE were asked to select the key external determinant at the macroenvironmental level, which represents the largest barrier for their business activities. This question is related to hypothesis $H_{1}$, while the respondents could choose from the following determinants: political and legal; economic; demographic; social-cultural; technological and informational; and ecological. Concluding from the results of the questionnaire, the political and legal determinants represent the biggest problem in conducting family business in Slovakia $(67.8 \%)$. The second most negatively perceived group of determinants is the economic ones (29.3\%). Hypothesis $H_{l}$ was verified by the Binomial test, while the results show that it is possible to confirm the validity of hypothesis $H_{1}$, i.e. most MSMFE in Slovakia consider the group of political and legal determinants to be the factor which influences their business activities most negatively at the macro-environmental level ( $p$ value $=0.000$ ). In the second question of this part of the research, determinants influencing micro-environment were examined. Respondents were asked to choose three determinants which they considered to be most problematic with regard to their business. The list of determinants to choose from was as follows: competition in the market; the level of development of the given industry; problems with suppliers; lack of knowledge about the foreign market(s) needed to increase the operations of their enterprise; bad payment morale of customers; disinterest of customers in products; and the ineffective cooperation with intermediaries. All addressed FE have indicated that the most negative determinant was the existing competition. The second most frequently mentioned determinant was bad payment morale of customers $(56.1 \%$ of the addressed FE), followed by lack of knowledge about the foreign market(s) needed to increase the operations of the enterprise $(48.5 \%)$. The question aimed at examining the micro-environment of family businesses relates to hypothesis $\mathrm{H}_{2}$. This hypothesis was tested by the Friedman test, followed by the Wilcoxon test. The results of the Friedman test confirmed that the individual determinants of the micro-environment are not of the same significance $(\mathrm{p}$-value $=0.000)$. The Wilcoxon test enabled identification of the ranking of importance of the individual determinants. It can thus be stated that the main external problem of Slovak MSMFE at the microenvironmental level is the competition of other enterprises operating in the Slovak market ( $\mathrm{p}$-value $=0.000$ ). Hypothesis $\mathrm{H}_{2}$ was confirmed .

In the last part of the research questionnaire, attention was given to investigating the internal environment of FE. At the beginning of the fourth part of the questionnaire, the authors placed questions which related to hypothesis $H_{3}$. So as to enable verification of the hypothesis, it was necessary to find out if Slovak FE possess a family protocol. According to the research results, only $32 \%$ of the addressed family enterprises currently possess a family protocol. It was further necessary to examine how FE perceive the individual selected determinants of the internal environment of their enterprise. In this question, respondents were asked to select from a three-point scale (positively; do not know; negatively) for each determinant. Among the most negatively perceived determinants of the internal environment of FE belong: long-term planning of the succession in the enterprise, the method of taking over the enterprise, and the selection method of the successor $(70.9 \%$ of the addressed FE), a plan of continuous education of employees (70.7\%), nepotism $(70.2 \%)$, and the elaboration of a strategic plan, objectives and visions of the enterprise $(69.9 \%)$. On the other hand, among the most positive determinants perceived by FE are: social responsibility for all employees $(61.7 \%)$, and the overlaps between the family and corporate relations $(38.4 \%)$. In order to statistically verify hypothesis $\mathrm{H}_{3}$, the MannWhitney test of the SPSS program was used. The Mann-Whitney test confirmed the 
validity of hypothesis $\mathrm{H}_{3}$, which indicates that those $\mathrm{FE}$ that do not have a family protocol perceive the determinants of their internal environment as more negative in comparison with those who possess this protocol $(\mathrm{p}$-value $=0.000$ ).

Problems of the internal environment of enterprises may often threaten their existence. The last question focused on identifying the main internal problems of FE. In this question, respondents were asked to select three most problematic determinants of their internal environment. The last question thus enabled verification of hypothesis $H_{4}$. Within the questionnaire, it was found out that the biggest problem of the contemporary $\mathrm{FE}$ is to obtain a stable qualified workforce ( $92.4 \%$ of the addressed FE). Among other most frequently indicated internal problems are: providing requalification of the workforce (48.2\% of the addressed FE), lowering the costs (35.2\%), and the deficiencies in financial management $(34.7 \%)$. The least frequent appear to be the problems of FE with conflicts in family and work relations ( $2.6 \%$ of the addressed $\mathrm{FE}$ ), unclear competences among family employees (3.6\%), and insufficient qualification of family employees $(7.7 \%)$. Hypothesis $\boldsymbol{H}_{4}$ was tested by Friedman and Wilcoxon tests. Friedman test has shown that the individual determinants are not of the same significance ( $p$-value $=0.000$ ). The Wilcoxon test enabled identification of the ranking of significance of the individual determinants. As it can be concluded from the results, the most negative determinant of the internal environments of FE is obtaining a stable qualified workforce. From the above results, it can be stated that Friedman and Wilcoxon tests confirmed hypothesis $\mathrm{H}_{4}$, which means that the main internal problem of Slovak MSMFE is the inability to obtain a stable qualified workforce.

By summarizing the research results obtained from the questionnaire, the following conclusions were formulated. The research sample was formed by MSMFE which operate actively and are listed in the trade register of the Slovak Republic. The representativeness of the selected sample was confirmed by the Chi-square test, and the results may be generalized and applied to all MSMFE in Slovakia. The conducted research has shown that $84 \%$ of micro, small, and medium enterprises which participated in the questionnaire fulfilled the condition of being a family enterprise, which indicates their dominant position in this group of enterprises. Similar results were achieved by foreign researches $[4,7]$, who confirmed the dominant position of FE in individual national economies. As the conducted research has proved, at the macro-environmental level, the most significant problem of $\mathrm{FE}$ appears to be the political and legal determinants (confirmed by hypothesis $\mathrm{H}_{1}$ ). The second most problematic determinant was the economic factors of the business environment in Slovakia. The results of the research relating to external determinants corresponds with conclusions of [8], who determined the weaknesses of the Slovak BE by business environment indexes. As to micro-environment, the most negative determinant that limits the activities of FE is strong competition of Slovak and foreign enterprises operating in the Slovak market (verified by hypothesis $\mathrm{H}_{2}$ ). Among other significant problems of $\mathrm{FE}$ at the micro-environmental level are: bad payment morale of customers, and the lack of knowledge about the foreign market(s) needed to increase own operations of the enterprise. These problems, as noted by [8], are common among all SMEs in Slovakia. At present, various measures are taken in order to eliminate these problems. However, as pointed out by [6], with regard to the openness of Slovak economy, it is not possible to restrict business operations of foreign enterprises in the country. It is suggested that in order to eliminate the negative determinants of the external environment (at both the macro and micro levels), FE could be assisted by being defined as an entrepreneurial unit, and being incorporated into the existing legislation and the initiatives aiming at supporting SMEs. As presented by [14], following the example of the western countries of the EU, it would be appropriate to create organizations that would represent the interests of FE at the national level. Further, the attention was given to examining the internal determinants of FE. The research has revealed 
that those FE which possess a family protocol perceive the determinants of their internal environment more positively in comparison with those who do not possess this document (verified by hypothesis $\mathrm{H}_{3}$ ). Foreign authors [7, 18,19] point out that family protocol and the process of its elaboration is of a great significance for both the enterprise and the owner's family. The past experience authenticated by business practice has shown that without defining and achieving agreement on the basic principles, and without their correction according to potential expectations of the family members with regard to the enterprise, with the rising number of family members, the risk of destructive conflicts within the family and the enterprise will grow as well. Only by uniting the individual interests of the family with the interests of the enterprise, it is possible to achieve sustainability of the enterprise for future generations. The biggest problem related to internal environment of $\mathrm{FE}$ is obtaining a stable qualified workforce (confirmed by hypothesis $\mathrm{H}_{4}$ ). Similar results were achieved by foreign researchers $[4,14,17]$, who have observed that external employees often work in the FE for several years, and after achieving their own experience, they leave the enterprise which invested into their development, in order to establish their own enterprises. For FE, this represents a great loss, and it forces them to search new qualified employees in the job market. In order to support and sustain FE in Slovakia, and with regard to the identified state of the issue, it would be appropriate to implement consultancy in the field of management, as well as in helping enterprises to establish their own family protocols. Further, it would be largely helpful to assist FE in creating strategies of succession, and in training the skills needed to manage the process of generational exchange. At the same time, it is necessary to provide support regarding promotion of FE in Slovakia, mainly in a form of informational events promoting an individual FE. As agreed by [15], it is essential to implement such tools of financing which would be oriented specifically on supporting family enterprises. More awareness and more attention to FE should be given by Slovak universities, mainly of the economic field, as well as the by state institutions, especially the Statistical Office, and the Slovak Business Agency.

\section{Conclusion}

Family business undoubtedly deserves more attention, mainly on the part of national governments, which should use appropriate tools to support creating new, as well as sustaining the already existing, family enterprises. It is essential for FE not to remain 'hidden' from sight by being taken as a part of category of micro, small, and medium enterprises (large enterprises respectively), and to be given individual attention. At the same time, it is necessary to adopt a unified definition of family business accepted worldwide, which would help these enterprises, but also enable academics and scholars to investigate the insights of family business in more detail.

This paper has been supported by funds of the project VEGA No. 1/0010/17 and projects, APVV-170456, APVV-17-0583, APVV-18-0520 and APVV-18-0378.

\section{References}

1. L. Kloviene, Institutional Factors as Criteria for Business Environment Identification. Economics and Management. Economics and Management 17, 4 (2012)

2. R. Hernandez-Linares, W. F. Kellermanns, M. C. Lopez-Fernandez, A note on the relationships between learning, market, and entrepreneurial orientations in family and nonfamily firms. Journal of Family Business Strategy 9, 3 (2018) 
3. J. F. Hennart, A. Majocchi, E. Forlanj, The myth of the stay-at-home family firm: How family-managed SMEs can overcome their internationalization limitations. Journal of International Business Studies 50, 5 (2019)

4. G. Solomon, Entrepreneurship in Family Firms, Business Families, and Family Business Groups. Journal of Small Business Management 54, 1 (2015)

5. P. Vazquez, H. Rocha, On the goals of family firms: A review and integration. Journal of Family Business Strategy 9, 2 (2018)

6. S. M. Wagner, The Business Environment of Europe: Firms, Governments, and Institutions. Academy of Management Learning \& Education 16, 1 (2017)

7. R. Evert, J. A. Martin, M. S. McLeod et al., Empirics in Family Business Research: Progress, Challenges, and the Path Ahead. 2016. Family Business Review 29, 1 (2016)

8. Ch. Gaganis, F. Pasiouras, F. Voulgari, Culture, business environments and SMEs' profitability: Evidence from European Countries. Economic Modelling 78, 275-292 (2019)

9. N. O. Ndubisi, A. Nygaard, C. Capel, Mindfulness-based business strategies and the environment. Business Strategy and the Environment 28, 3 (2019)

10. J. M. Jasra, Determinants of Business Success of Small and Medium Enterprises. International Journal of Business and Social Science 2, 20 (2011)

11. L. J. Stanley, R. Hernandez-Linares, M. C. Lopez-Fernandez et al., A Typology of Family Firms: An Investigation of Entrepreneurial Orientation and Performance. Family Business Review 32, 2 (2019)

12. Y. B. Kraja, E. Osmani, Importance of External and Internal Environment in Creation of Competitive Advantage to SMEs. European Scientific Journal 11, 13 (2015)

13. E. Pindiche, R. Ionita, The Influence of Micro and Macro Environment Components on Trade Companies in Romania. Journal of Knowledge Management, Economics and Information Technology 24, 12 (2013)

14. J. C. Casillas, A. M. Moreno-Menendez, J. L. Barbero et al., Retrenchment Strategies and Family Involvement: The role of Survival Risk. Family Business Review 32, 1 (2019)

15. O. Machek, J. Hnilica, M. Brabec, Characteristic of Family Businesses in the Czech Republic. European Scientific Journal 4, 66-72 (2013)

16. A. Hernández-Trasobares, C. Galve-Górriz, Diversification and family control as determinants of performance: A study of listed business groups. European Research on Management and Business Economics 23, 1 (2017)

17. J. Karlsson, Does regional context matter for family firm employment growth? Journal of Family Business Strategy 9, 4 (2018)

18. B. Villalonga, R. Amit, How do Family Ownership Control and Management Affect Firm Value? Journal of Financial Economics 80, 2 (2006)

19. H. Chung. The Role of Family Management and Ownership on Semi-globalization Pattern of Globalization: The case of Family Business Groups. International Business Review 23, 1 (2014) 